\title{
Stability assessment of enzyme stabilized road embankments
}

\author{
Jaspreet Singh $^{1}$, Dilan Robert ${ }^{1 *}$, Peihan Wang $^{1}$, Filippo Giustozzi ${ }^{1}$, Mojtaba \\ Mahmoodian ${ }^{1}$, Sujeeva Setunge ${ }^{1}$ and Brian O’Donnell ${ }^{2}$ \\ ${ }^{1}$ Civil Engineering, RMIT University \\ ${ }^{2}$ Center for Pavement Excellence Asia Pacific
}

\begin{abstract}
Road infrastructure is one of the most important factors for a country's development. The vital role that they play in the present economy is reflected in many kilometres of roads worldwide. The external loads due to recurring traffic loads and geohazards can result in road failures with consequences in terms of economic loss to asset managers, public safety and vehicle damage. Due to such adverse effects of road failures, soil stabilization is being widely used as a preventive measure of road failures since recently. However, the assessment (or design) of stabilized road embankments using current standards assume linear material response and two-dimensional geometric idealization. Such assumptions can lead to non-conservative results, leading the road embankments to fail in long-term mainly due to improper assessments in the designs. The current research investigates the assessment of enzyme based stabilized road embankments under external traffic loads using threedimensional (3-D) finite element (FE) analysis. Firstly, laboratory tests were conducted to characterize the soil/stabilized soil and to calibrate the numerical models. Then, a series of FE analyses were conducted to investigate the performance of stabilized road embankments under external traffic loads. Results showed that the prediction of required pavement thicknesses using elasto-plastic 3-D modelling could be substantially different in comparison to the results obtained from available standard pavement design tools and 2-D idealization of pavement modelling. The study revealed the importance of considering realistic material performance and load applications during the assessment of pavement design in order to maximize the benefits of enzyme stabilization that can be effective in prevention of the road embankment failures.
\end{abstract}

Keywords: road embankments, enzymes, finite element analysis, traffic loads, pavement design, laboratory tests

\footnotetext{
* Corresponding author: dilan.robert@,rmit.edu.au
} 


\section{Introduction}

Road infrastructure paves the way for a country's growth and development, particularly in developing countries where road infrastructure has a major influence on economic growth [1]. Road infrastructure stimulates economic activates, improves competitiveness with reduced transportation costs and provides employment opportunities [1]. Failure of this vital infrastructure has detrimental consequences resulting in direct and indirect costs. Direct costs include economic losses due to damages to the road infrastructure whereas indirect costs involve the consequences that the damaged road infrastructure has on society [2]. Within the U.S., annual direct cost exceeds $\$ 100$ million, whereas annual indirect cost equates to or exceeds direct costs [3]. On one hand, asset managers are faced with economic losses as the road asset that provides services to the public fail and/or become damaged, affecting long term management and maintenance of this vital infrastructure [4]. Further, it can result in fatalities and injuries, in addition to extended road closures due to resulted debris from the road failure [5].

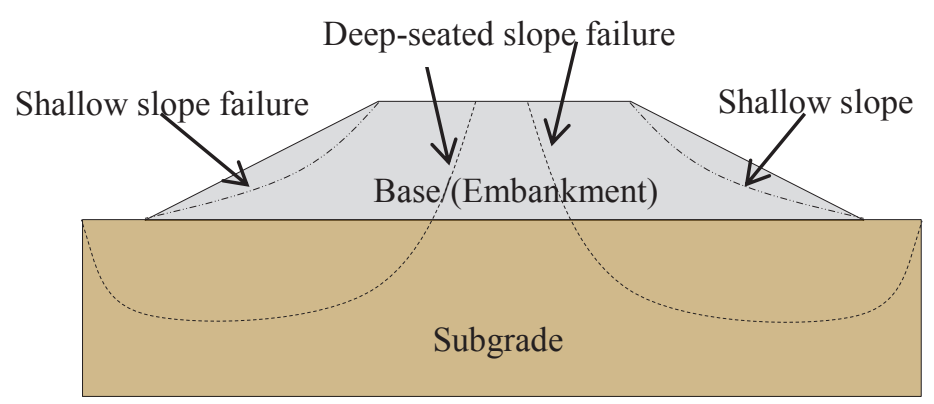

Fig. 1. Potential slope stability failure on a road embankment.

Failures of road embankment can happen when the driving forces exceed the resisting forces from the shear strength of the soil. Driving forces include; external loading from recurring traffic loading and geohazards from rainfall, erosion and earthquakes. Such embankment failures can be identified as a slope failure which can either occur through the embankment as shallow slope failure or deep-seated slope failure [6, 7], as showed in Fig. 1. Deep-seated failures typically occur due to weak foundation soils or after long periods of heavy rainfall, whereas shallow failures commonly occur due to short periods of intense rainfall $[7,8]$. The type of failure can be governed by pavement thickness, soil initial condition (embankment and subgrade) and the type of loading applied on the road pavement. However, consequence of failure either due to shallow or deep-seated failure can lead to serviceability concerns and the repair/remediation costs can be substantial. The annual costs of shallow slope failures have been estimated to exceed the repair of deepseated slope failures [3]. The repair costs of each individual shallow slope failures are low, however due to its common occurrence, the total cumulative costs are extensive [3].

Significant effort has been made in the past to prevent the failure of road embankments through stabilization. Stabilization increases the resisting forces with enhanced shear strength of the soil and reduces the imposed driving forces [9]. Engineers and researchers have adopted numerous stabilization methods for embankments. The current practices adopted by engineers to stabilize shallow slope failures include rebuilding failed slopes, use of geosynthetics, soil nailing and chemical stabilization. However, they do not often provide the most economical stabilization solution. Rebuilding of a failed slope with the failed material is a quick remedial, but is uneconomical in the long term [10]. There are added costs associated with geosynthetic material used in reinforced soil slopes; including; purchasing, transportation and installation [10]. Installation of soil nails can cause 
displacements in the surrounding wall and its construction and design provisions are expensive [11]. Similarly, the use of lime in embankment stabilization is not the most economical alternative available [12]. On the other hand, enzyme stabilization can be an effective and economic alternative to prevent road embankment failures.

Enzymes are organic catalysts, derived from plants and animals that increase the rate of specific chemical reactions, without being consumed itself. For this reason enzymes are used in low concentrations. Enzymes require mobility to reach the reaction site for it to become activated. Pore fluid in the soil mass provides the required mobility, soil chemistry provides the specific reaction site and time ensures the reaction occurs [13, 14]. Clay soil molecules have a net negative charge, to maintain neutrality; they are attracted to positively charged particles. The negative charge attracts the polarized water molecules, resulting in a water molecules attached and absorbed around the clay soil molecules causing shrinking and swelling of the soil, hence, the properties of clay soil is improved by reducing the amount of absorbed water [14]. Enzyme stabilizers bond with organic molecules, accelerating the reactions between clay soil molecules and the organic cations and accelerate cationic exchange [14]. Consequently, this neutralises the clay molecules negative charge, and thus prevents water absorption and density loss, allowing for soils to become denser [13, 14]. Like other stabilization approaches, enzymes improve and strengthen the soil properties. Some stabilization methods require long cure times or have lengthy stabilization processes and require large quantities, however enzymes provide viable alternative [15]. Enzyme stabilization increases the CBR and durability, reduces the optimum moisture content and plasticity, reduces the soils affinity to water and ensures the recycling of in-situ material $[14,16,17]$. Researchers have found that the unconfined compressive strength (UCS) increases with the use of enzyme soil stabilizers $[15,18]$. Enzyme stabilizers have been implemented in the construction of roads to improve the engineering properties of weak soil materials [17]. Enzymes are in liquid concentration form and require dilution; the application process varies between products [16]. At current, there is no model to predict and design stabilized slopes using enzymes. In addition, no standard method exists for the application or testing of enzyme stabilizers in road embankment construction and often manufactures methods are inadequate [15].

Traditionally, the slope stability analysis is expressed as a factor of safety (FOS). Slope stability is determined from limit equilibrium (LE) methods based on assumptions regarding the slip surface [19]. LE method is widely used by engineers due to its level of simplicity; however, the method assumes the FOS is the same along the slip surface, without considering the behaviour of the soil, thus failing to capture the real failure mechanisms of the slope $[19,20]$. On the other hand, finite element (FE) analysis can be an effective alternative to overcome these limitations. It provides an understanding of stresses, movements and pore pressures within the slope by using the actual stress-strain characteristics of the soil [20-22]. The improved accuracy and capability of the FE analysis allows slope stability to be monitored and the exact failure mechanism to be obtained [23]. Various slope stability problems have been assessed using numerical modelling [8, 24, 25].

The current approach in the stability assessments of road embankments predominantly assumes 2-D geometric idealizations and linear material behaviour. Unbound pavements are designed using the elastic properties of the material [26]. The practising standard pavement design tools assume material linearity and 2-D geometry/loading simplifications. The performance of unbound pavements subjected to traffic loading have been studied using 2-D elastic FE modelling [27]. Slope stability of embankments have also been determined from 2-D FE models with elasto-plastic behaviour of material [24, 25]. A 2-D model geometry is an over simplification of a 3-D problem. In the 2-D limit equilibrium model, the slip surface is assumed and is infinite and parallel to the slope. Further, traffic loading may not be represented realistically in 2-D modelling as vehicular loads apply 
pressure on the pavement via patch (i.e. circular) area rather than point or line loading as simulated in 2-D modelling. The approach using 3-D FE modelling can eliminate such simplifications, resulting in a more accurate slope stability analysis and pavement design.

The current research investigates the assessment of enzyme based stabilized road embankments under external traffic loads using three-dimensional (3-D) finite element (FE) analysis. Firstly, laboratory tests were conducted to characterise the soil/stabilized soil and to calibrate the numerical models. Then, a series of FE analyses were conducted to investigate the performance of stabilized road embankments under external traffic loads. Results showed that the prediction of required pavement thicknesses using elasto-plastic 3$\mathrm{D}$ modelling could be substantially different in comparison to the results obtained from available standard pavement design tools and 2-D idealization of pavement modelling. The study revealed the importance of considering realistic material performance and load applications during the assessment of pavement design in order to maximize the benefits of enzyme stabilization that can effectively prevent the road embankment failures.

\section{Methodology}

The investigations of the current study are based on laboratory experiments and numerical modelling. Laboratory tests were first conducted on a clay soil obtained from a land excavation site in Melbourne, Australia. Having obtained the soil characteristics of stabilized and non-stabilized soils, a series of FE analysis was conducted to investigate the performance of stabilized road embankment under external traffic loads. The results are compared with standard pavement design predictions to investigate the applicability of current practising tools, which assume material linearity and 2-dimensional approximation of pavement.

\section{Laboratory tests}

Laboratory tests, such as hydrometer test, Atterberg test and compaction tests were conducted on the selected clay soil for material characterization (Table 1). A series of direct shear tests was conducted on samples obtained from the stabilized soil mix at various enzyme weights and dilution contents prepared at the optimum moisture and maximum dry density condition. The selected results of the tests are presented in Fig. 2 for enzyme weight of 5\% (by dry weight) at the dilution content of 1:500. The soil strength characterization is presented in Table 2 .

Table 1. Soil characterization from laboratory tests.

\begin{tabular}{|c|c|}
\hline Description & Value \\
\hline Soil Type & Low plasticity clay \\
\hline Liquid Limit & 28.6 \\
\hline Plastic Limit & 20.4 \\
\hline $\begin{array}{c}\text { Optimum moisture } \\
\text { (OMC) }\end{array}$ & $14.8 \%$ \\
\hline $\begin{array}{c}\text { Maximum dry } \\
\text { density (MDD) }\end{array}$ & $1.9 \mathrm{~g} / \mathrm{cm}^{3}$ \\
\hline Initial Suction & $100 \mathrm{kPa}$ \\
\hline
\end{tabular}

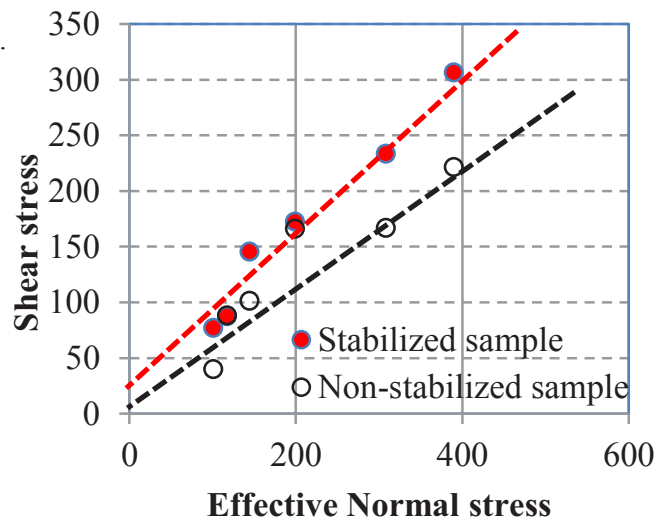

Fig. 2. Direct shear test data for enzyme weight $5 \%$ \& dilution 1:500 
Table 2. Soil strength characterization.

\begin{tabular}{|c|c|c|c|c|c|c|}
\hline & $\begin{array}{l}\text { Density } \\
\left(\mathrm{g} / \mathrm{cm}^{3}\right)\end{array}$ & $\begin{array}{c}\text { Elastic } \\
\text { Modulus }^{1} \\
(\mathrm{kPa})\end{array}$ & $\begin{array}{l}\text { Poisson's } \\
\text { ratio }\end{array}$ & $\begin{array}{c}\text { Cohesion } \\
\quad(\mathrm{kPa})\end{array}$ & $\begin{array}{c}\text { Friction } \\
\text { angle }{ }^{2} \\
\text { (degrees) }\end{array}$ & $\begin{array}{c}\text { Dilation } \\
\text { angle }{ }^{2} \\
\text { (degrees) }\end{array}$ \\
\hline Stabilised & 1.85 & 150000 & 0.3 & 22 & 34.2 & 15 \\
\hline $\begin{array}{c}\text { Non- } \\
\text { Stabilised }\end{array}$ & 1.85 & 80000 & 0.3 & 5 & 25.6 & 5 \\
\hline
\end{tabular}

\section{Pavement Geometry}

In order to select the geometry for numerical modelling, the road embankment was designed according to the Austroads [26] design guidelines, assuming a rural class road with a traffic load of $1.0 \times 10^{5} \mathrm{ESA}$, an allowable strain limit of $1.796 \times 10^{3}$ and terminal rutting of $20 \mathrm{~mm}$ [28]. Allowable strain limit at the subgrade and rutting has been determined based on guidelines $[26,28]$ and a standard pavement design tool (CIRCLY). For this selected design consideration, the empirical design and mechanistic design (CIRCLY) required a cover of $220 \mathrm{~mm}$ and $250 \mathrm{~mm}$, respectively. The roadway design was assumed to be consisting of typical 2-lane rural road with $3.1 \mathrm{~m}$ lane width $(6.2 \mathrm{~m}$ total width). The road embankment is designed with 2:1 slopes, subgrade depth of $5 \mathrm{~m}$ and a varying base depth. The selected slope geometry is due to non-recoverability of steeper slopes ( $>4: 1)$ by traversing cars [29]. Fig. 3 shows the geometry of the derived pavement considered in this study.

\section{FE Model}

Three dimensional (3-D) and two dimensional (2-D) finite element analyses were carried out using ABAQUS to investigate the behaviour of road embankments during traffic loading. The pavement and the subgrade soil were represented by 8 -noded brick reduced integration elements and 8-noded plane strain reduced integration elements in 3-D \& 2-D models respectively. The soil side boundaries of the FE model were assumed to be smooth and are located far (i.e., $2.5 \mathrm{~m}$ ) from the traffic loads to eliminate any boundary effects. Figure 3 shows the mesh discretization and model dimensions. The applied traffic load on the pavement surface is based on single-axle-dual-tyre (SADT) configuration having total axle load of $80 \mathrm{kN} \mathrm{[26].}$
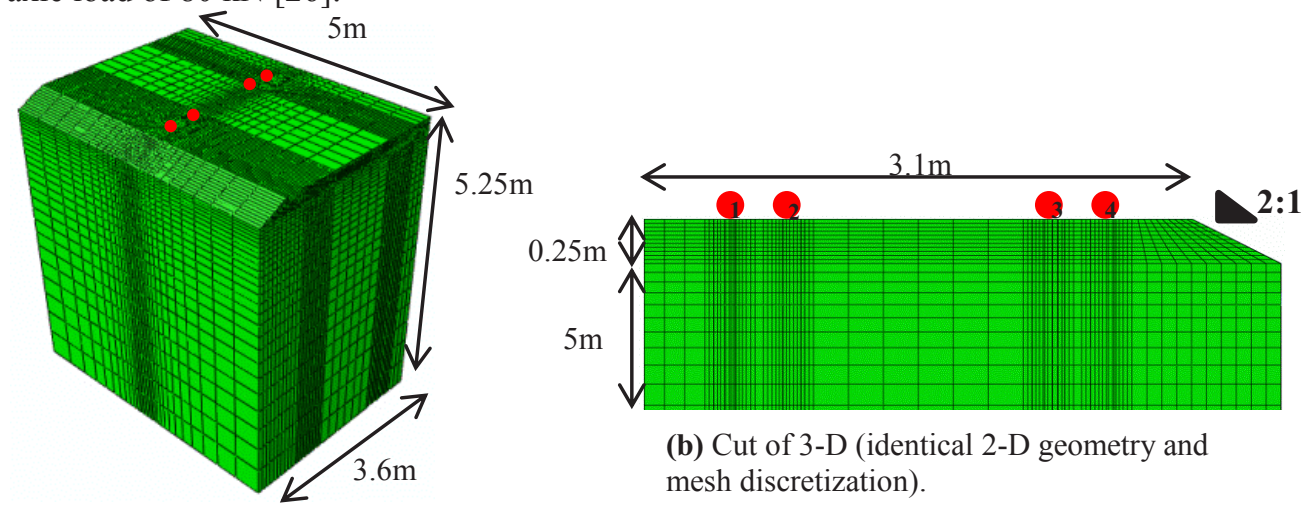

(b) Cut of 3-D (identical 2-D geometry and mesh discretization).

(a) 3-D geometry and mesh discretization.

Fig.3. Geometry and mesh discretization of FE model. 


\section{Analysis Plan}

Firstly, the analyses were conducted using 3-D \& 2-D FE models under traffic loading with linear-elastic material response (Stage 1) for stabilized and non-stabilized pavements. This is to investigate the effect of geometry and loading between 3-D and 2-D (including standard tools) idealizations. Secondly, analyses were performed to study the significance of considering material non-linearity on the selection of stabilized/non-stabilized pavement thicknesses (Stage 2). Finally, a parametric study (with the change in base thicknesses) was conducted to determine the required stabilised base thickness when realistic geometry, loading and material are encountered (Stage 3). In all the analysis, the subgrade depth was kept constant (i.e., $5 \mathrm{~m}$ ) over the models, while the thickness of the base is varied in order to determine the suitable thickness, as seen in Figure 3

\section{Results/Discussion}

The results of the analysis conducted in stage $1 \& 2$ are summarized in Table $3 \&$ Fig. 4 for investigating the effect of geometry on pavement response for stabilized and non-stabilized materials. The results showed that the 2-D FE modelling of a road embankment does not provide a realistic representation. This is mainly due to the strip tyre pressure loading applied on the pavement rather than a realistic tyre (i.e., patch) loading. Similar to the standard pavement design tool (i.e., CIRCLY) predictions, the 2-D stabilized and nonstabilized pavement models with elastic material idealization satisfies the allowed strain $\left(1.796 \times 10^{-3}\right)$ and deformation (20 mm rutting) limits of the pavement as showed in Table 3. However, when non-linearity of the soil is considered within the 2-D modelling framework, pavement fails under both stabilized and non-stabilized conditions of the pavement. This is because of substantial yield induced by 2-D strip loading on the pavement material during traffic loading. The mechanism of failure and shear band formation in the 2-D road embankment is showed in Fig. 4a, which reveals the failure of the road embankment can be due to combined mechanism of shallow and deep soil failures.

3-D FE modelling provides a realistic representation of SADT loading on the road embankment. Similar to what was obtained from 2-D models \& CIRCLY analysis, the maximum subgrade strains and ground surface rutting are within allowed limits under elastic stabilized and non-stabilized material conditions (Table 3). However, the road embankment fails when the material was simulated as elasto-plastic for stabilized pavement. Therefore, the pavement, which was accepted under standard pavement design tools and 3-D elastic material idealization, failed due to high deformation of pavement material resulted in soil yielding. This reveals the importance of considering material nonlinearity when assessing the stability of stabilized road pavements. The failure mechanism of the 3-D pavement model showed in Fig. 4b (cut from the 3D model across the loading axle direction) which shows the road embankment failure has resulted mainly due to subgrade soil failure.

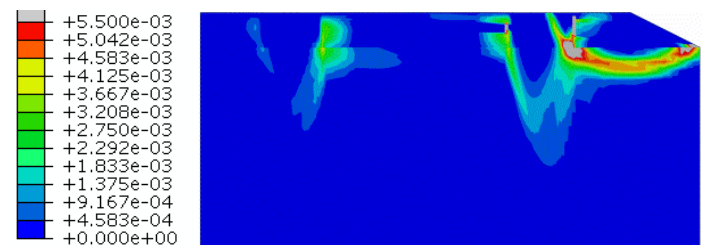

(a). 2-D geometry (30\% loading)

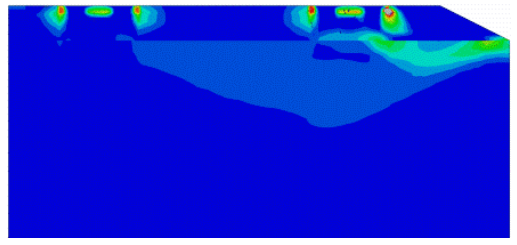

(b). 3-D geometry (100\% loading)

Fig.4. Plastic strain and shear band formation in the FE models 
Table 3. Strain and rutting in embankment based on different approaches.

\begin{tabular}{|c|c|c|c|c|c|}
\hline Analysis & Dimension & $\begin{array}{c}\text { Base } \\
\text { Treatment }\end{array}$ & $\begin{array}{c}\text { Pavement } \\
\text { Idealisation }\end{array}$ & $\begin{array}{c}\text { Strain at } \\
\text { Subgrade, Slope } \\
\text { Side (between } \\
\text { tyres) }\end{array}$ & $\begin{array}{c}\text { Rutting } \\
\text { (mm) }\end{array}$ \\
\hline Circly & 2-D & Stabilised & Elastic & 0.00179 & \\
\hline FE & 2-D & Stabilised & Elastic & 0.00142 & 11.8 \\
\hline FE & 2-D & $\begin{array}{c}\text { Non- } \\
\text { Stabilised }\end{array}$ & Elastic & 0.00147 & 12.6 \\
\hline FE & 2-D & Stabilised & $\begin{array}{c}\text { Elasto-plastic (with } \\
30.20 \% \text { loading) }\end{array}$ & 0.00721 & 5.8 \\
\hline FE & 2-D & $\begin{array}{c}\text { Non- } \\
\text { Stabilised }\end{array}$ & $\begin{array}{c}\text { Elasto-plastic (with } \\
14.45 \% \text { loading) }\end{array}$ & 0.00148 & 4.3 \\
\hline FE & 3-D & Stabilised & Elastic & 0.000527 & 0.48 \\
\hline FE & 3-D & $\begin{array}{c}\text { Non- } \\
\text { Stabilised }\end{array}$ & Elastic & 0.000569 & 1.03 \\
\hline FE & 3-D & Stabilised & Elasto-plastic & 0.00185 & 0.74 \\
\hline \multicolumn{7}{|r|}{ FE } & 3-D & $\begin{array}{c}\text { Non- } \\
\text { Stabilised }\end{array}$ & $\begin{array}{c}\text { Elasto-plastic (with } \\
27.30 \% \text { loading) }\end{array}$ & 0.000690 & 8.24 \\
\hline \multicolumn{2}{|l}{ Allowable strain: 0.001796, Terminal rutting 20 mm } \\
\hline
\end{tabular}

The effectiveness of enzyme stabilization can be identified from the maximum strains resulted at the subgrade soil (Fig. 5). Results revealed that when the base is treated with enzyme stabilisation, the strains experienced at the subgrade level are significantly lower than the subgrade strains resulted in non-stabilized road pavement. This can be identified as an improvement of the road performance due to stabilization. i.e. enzyme stabilization has increased the shear strength of soil, enhancing the overall road performance. It can be seen that the subgrade strains getting attenuated towards the slope side due to the loading interaction with the slope. Such response reveals the importance of stabilizing slopes as the road embankment failure is triggered at the slope side of the road.

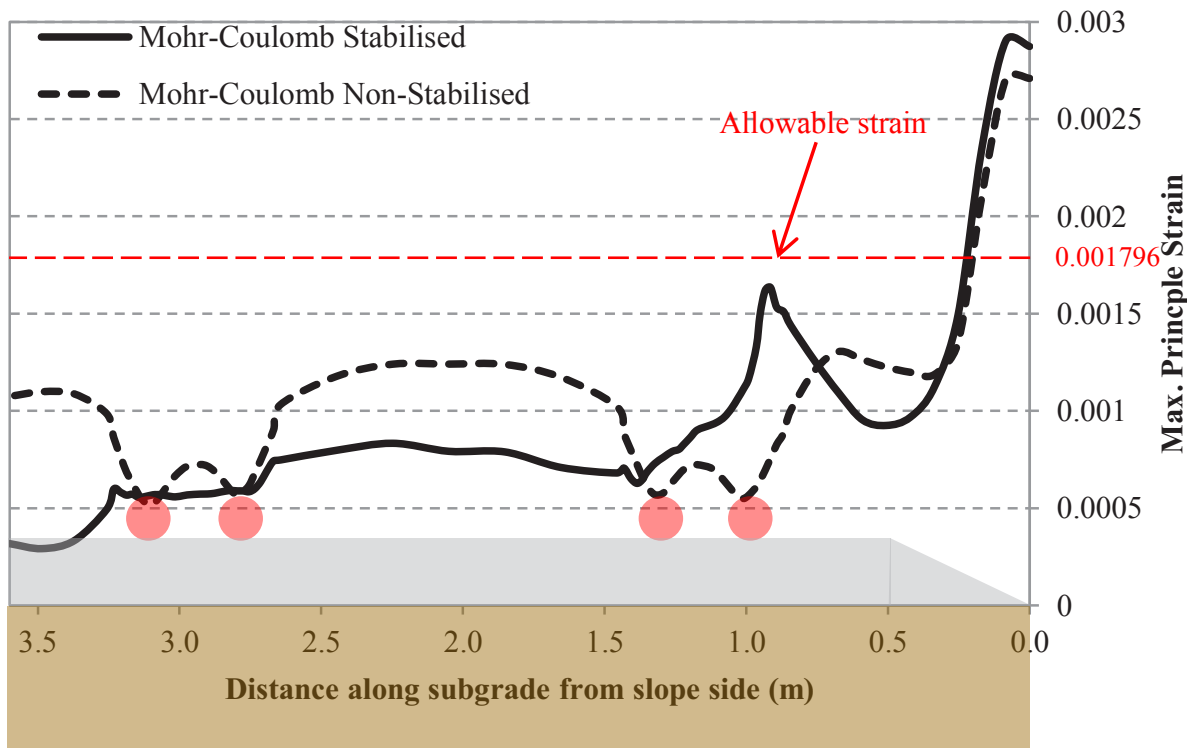

Fig.5. Strain along subgrade due to SADT loading 
The results of the parametric study conducted to investigate the adequate stabilized pavement thicknesses is summarised in Fig. 6. It can be seen that the subgrade strain decreases with the increase in treated base (embankment) thickness. The stabilized base thickness required to satisfy the allowed strains in the subgrade $\left(1.796 \times 10^{3}\right)$ is identified as $300 \mathrm{~mm}$ using the 3-D FE model which incorporates elasto-plastic material response. On the other hand, the standard pavement design tool shows that a base thickness of $250 \mathrm{~mm}$ is adequate to satisfy the allowable strains, indicating an under-prediction of $20 \%$ for the stabilized layer thickness under the selected design consideration. This highlights the importance of considering the realistic material and geometric idealizations when assessing the stability of stabilized road pavements.

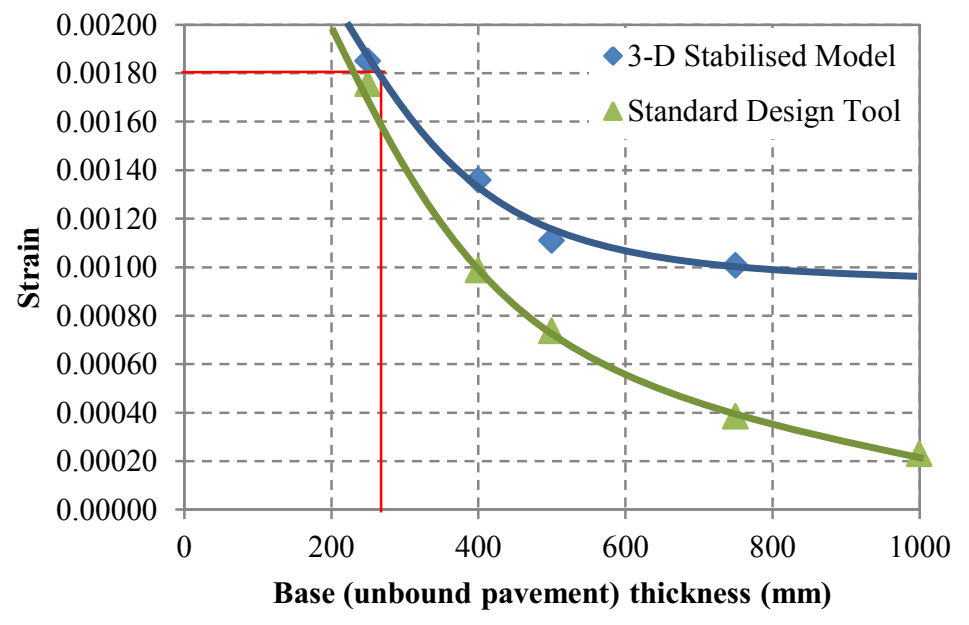

Fig.6. Comparison of strains at various bases thicknesses using 3-D FE analysis (using MohrCoulomb plasticity) and standard design tool

\section{Conclusions}

The current research investigates the assessment of enzyme based stabilized road embankments under external traffic loads using finite element analysis. Firstly, laboratory tests were conducted to characterise the soil/stabilized soil and to calibrate the numerical models. Then, a series of 2-D \& 3-D FE analyses were conducted to investigate the performance of stabilized road embankments under external traffic loads. The results showed that the 2-D FE modelling of a road embankment subjected to traffic loading does not provide a realistic model response due to the strip pressure loading applied on the pavement surface rather than more rational circular patch loading which can be closely simulated using 3-D FE modelling. Results also revealed that, similar to standard design outcomes, the predictions from the numerical models for stabilized road performance are within acceptable deformations when the material behaviour is simulated under elastic idealization. However, the road embankment reaches serviceability failure under the same traffic loading when the stabilized material is simulated using elasto-plastic soil behaviour. The thickness of stabilized base required to satisfy the allowable strains is $20 \%$ higher than what is predicted using standard design tools and 2-D/3-D elastic modelling approaches. Thus, the results from the current study implies the importance of considering the realistic material and geometric idealizations when assessing the stability of stabilized road pavements. It is to be noted that the initial moisture (or suction) of the stabilized soil can also influence the overall response of the road embankment subjected to external loading. 
The study is being continued at present to investigate the pavement behaviour that can be captured within triple-hardening framework of stabilized soil ('stabilized + unsaturated' cohesion enhancement, 'stabilized + unsaturated' dilation enhancement and strain hardening).

\section{References}

1. P. Sahoo and R.K. Dash, Economic growth in South Asia: role of infrastructure. Institute of Economic Growth. (2008)

2. L. Masiero and R. Maggi, Estimation of indirect cost and evaluation of protective measures for infrastructure vulnerability: A case study on the transalpine transport corridor. Transp. Policy. 20: p. 13-21. (2012)

3. J. Loehr, T. Fennessey, and J. Bowders, Stabilization of surficial slides using recycled plastic reinforcement. Transport. Res. Rec.,(1989): p. 79-87. (2007)

4. S. McNeil and P. Herabat, Asset Management, in The Handbook of Highway Engineering. CRC Press. (2005)

5. M. Leiba, Impact of landslides in Australia to December 2011. Australian Journal of Emergency Management, The. 28(1): p. 28. (2013)

6. J. Han, et al., Evaluation of deep-seated slope stability of embankments over deep mixed foundations, in GeoSupport 2004: Drilled Shafts, Micropiling, Deep Mixing, Remedial Methods, and Specialty Foundation Systems. p. 945-954. (2004)

7. K. Briggs, F. Loveridge, and S. Glendinning, Failures in transport infrastructure embankments. Eng. Geol. p. 107-117. (2017)

8. F. Cai and K. Ugai, Numerical analysis of rainfall effects on slope stability. Int. J. Geomech. 4(2): p. 69-78. (2004)

9. L.W. Abramson, Slope stability and stabilization methods. John Wiley \& Sons. (2002)

10. R.W. Day, Design and repair for surficial slope failures. Practice Periodical on Structural Design and Construction. 1(3): p. 83-87. (1996)

11. F. Schlosser and P. Unterreiner, Soil nailing in France: research and practice. Transport. Res. Rec. 1330: p. 72-79. (1991)

12. R.B. Randolph, Earth materials catalyst stabilization for road bases, road shoulders, unpaved roads, and transportation earthworks. Transport. Res. Rec.,(1589): p. 58-63. (1997)

13. J. Tingle, et al., Stabilization mechanisms of nontraditional additives. Transport. Res. Rec.,(1989): p. 59-67. (2007)

14. M.R. Taha, et al., Recent Experimental Studies in Soil Stabilization with Bio-EnzymesA. Electronic Journal of Geotechnical Engineering. 18(R): p. 3881-3894. (2013)

15. J. Tingle and R. Santoni, Stabilization of clay soils with nontraditional additives. Transport. Res. Rec.,(1819): p. 72-84. (2003)

16. C. Stan and V. Ciobanu, Using enzymatic emulsions to reinforce road layers. Bulletin of the Transilvania University of Brasov. Forestry, Wood Industry, Agricultural Food Engineering. Series II. 5(1): p. 109-114. (2012)

17. V. Saini and P. Vaishnava, Soil stabilization by using terrazyme. International Journal of Advances in Engineering \& Technology. 8(4): p. 566-573. (2015)

18. R. Parsons and J. Milburn, Engineering behavior of stabilized soils. Transport. Res. Rec.,(1837): p. 20-29. (2003) 
19. J.M. Duncan, State of the art: limit equilibrium and finite-element analysis of slopes. J. Geotech. Eng-ASCE. 122(7): p. 577-596. (1996)

20. B. Khadija, et al., Slope Stability Evaluations by Limit Equilibrium and Finite Element Methods Applied to a Railway in the Moroccan Rif. Open Journal of Civil Engineering. 2(1): p.27. (2012)

21. D. Griffiths and P. Lane, Slope stability analysis by finite elements. Geotechnique. 49(3): p. 387-403. (1999)

22. K. Lim, et al., Slope-stability assessments using finite-element limit-analysis methods. Int. J. Geomech. 17(2): p. 06016017. (2017)

23. H. Zheng, D. Liu, and C. Li, Slope stability analysis based on elasto-plastic finite element method. Int. J. Numer. Meth. Eng. 64(14): p. 1871-1888. (2005)

24. S.W. Abusharar, J.-J. Zheng, and B.-G. Chen, Finite element modeling of the consolidation behavior of multi-column supported road embankment. Comput. Geotech. 36(4): p. 676-685. (2009)

25. J.-C. Chai, N. Miura, and S.-L. Shen, Performance of embankments with and without reinforcement on soft subsoil. Can. Geotech. J. 39(4): p. 838-848. (2002)

26. Austroads, Guide to Pavement Technology in Part 2: Pavement Structural Design Austroads Incorporated: Sydney, Australia. (2012)

27. K. Siripun, P. Jitsangiam, and H. Nikraz, The design model of unbound granular materials for flexible pavement.(technical paper)(Report). Aust. Civ. Eng. 10(1): p. 1. (2012)

28. G. Jameson and K.G. Sharp, Technical basis of Austroads pavement design guide. (2004)

29. Austroads, Guide to Road Design in Part 6: Roadside Design, Safety and Barriers Austroads Incorporated: Sydney, Australia. (2010) 